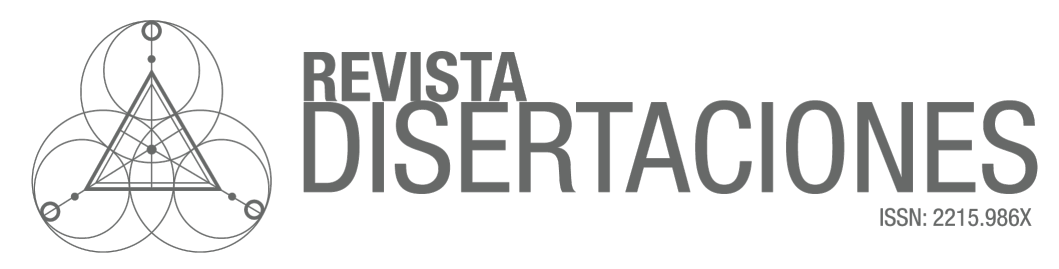

\title{
La disputa por la unidad en el discurso político colombiano: una lectura erística*
}

\section{Dispute for the Unity in the Colombian Political Discourse: An Eristic Reading}

\author{
Giohanny Olave Arias \\ Universidad Industrial de Santander - Colombia
}

\section{$\Phi$}

\section{Resumen}

El texto presenta una aproximación analítica a un corpus de comunicaciones emitidas por el expresidente Juan Manuel Santos y por la desmovilizada guerrilla de las Fuerzas Armadas Revolucionarias de Colombia, Ejército del Pueblo (FARC-EP), durante el bienio que precede al proceso de paz llevado a cabo en La Habana, Cuba. A partir de una lectura erística sobre los juegos de veridicción en torno a la idea de unidad, como objeto de discurso, se contraponen los componentes de cada construcción discursiva y se desmontan los mecanismos verbales a través de los cuales los actores sociales en disputa construyeron sentidos particulares sobre la unidad, en ese momento coyuntural del país. El examen en retrospectiva de esa disputa conduce a la interrogación del presente político en Colombia, en el cual la implementación de los acuerdos de paz firmados en 2016 se ha visto obstaculizada por la permanencia de esa lucha en torno a la verdad de los objetos de discurso disputados por los actores políticos.

Palabras clave: conflicto armado colombiano, análisis del discurso, discurso político, erística.

\footnotetext{
"Recibido: 30 de junio de 2020. Aceptado: 14 de septiembe de 2020.

Contacto: olavearias@ gmail.com
} 
La disputa por la unidad en el discurso político colombiano: una lectura erística

\begin{abstract}
This paper presents an analytical approach to a corpus of communications from the former President Juan Manuel Santos and the demobilized guerrilla FARC-EP, during the two-year period preceding the peace process in Havana, Cuba. Based on an eristic reading of the games of veridiction about the idea of unity as an "object of discourse", the components of each discursive construction are contrasted, and the verbal mechanisms through which the social actors in dispute constructed meanings are dismantled, in that conjunctural moment of the country. The retrospective examination of this dispute allows to interrogate the political present in Colombia, in which the implementation of the peace agreements signed in 2016 has been hindered by the continuity of this struggle for the truth of the objects of discourse disputed by political actors.
\end{abstract}

Keywords: Colombian Armed Conflict, Discourse Analysis, Political Discourse, Eristics.

$$
\text { (c) }{ }_{\mathrm{BY}} \text { (i) }
$$

Material publicado de acuerdo con los términos de la licencia Creative Commons AttributionNonCommercial-NoDerivatives 4.0 International (CC BY-NC-ND 4.0). Usted es libre de copiar o redistribuir el material en cualquier medio o formato, siempre y cuando dé los créditos apropiadamente, no lo haga con fines comerciales y no realice obras derivadas. 


\section{Introducción}

En febrero de 2012, mientras avanzaba la etapa secreta del proceso de paz que se firmaría en 2016, el jefe de la guerrilla de las FARC-EP le envió un comunicado al presidente Santos cuyo título irreverente llamó la atención de la prensa: Sin mentiras, Santos, sin mentiras. El tono directo con el que Timochenko increpaba al Jefe de Gobierno y se le plantaba como un interlocutor simétrico, desde la clandestinidad y la ilegalidad, anunciaba tras las líneas que los diálogos no significarían una rendición para la guerrilla, que ella se sentaría a la mesa más a reclamar que a negociar la paz, y que los discursos introducirían, de manera protagónica, el problema de la verdad en el tratamiento del conflicto armado interno.

En el período en el cual la tesis de la derrota militar de la guerrilla (el "fin del fin" de las FARC-EP) era contradicha por la reacomodación de los actores y de la guerra misma (2010-2012), los discursos gubernamental y guerrillero se volcaron hacia una disputa por mostrar lo que realmente estaba pasando en el país, esto es, por la definición de la verdadera realidad en tránsito. Este proceso de definir la situación, que en sociología ha sido estudiado de manera amplia, ${ }^{1}$ en clave retórico-argumentativa me lleva a interrogar

\footnotetext{
${ }^{1}$ Existe una numerosa bibliografía sociológica a partir del trabajo fundacional de William Thomas (27) y su famoso «teorema»: «hay una gran diferencia entre la situación, tal como los demás la ven, y la situación tal como esta le parece al individuo [...] Si los hombres definen sus situaciones como reales, estas son reales en sus consecuencias». Destaco aquí, por su relación con el concepto de esquema, en Grize (38), el desarrollo de los marcos de interpretación, a partir de la microsociología de Goffman: "Un marco se encuentra constituido por un esquema de interpretación que capacita a los individuos para ordenar sus vivencias dentro de su espacio de vida y del mundo en general" (53). La expresión "esquema interpretativo" alude a una herramienta o instrumento que se utiliza para ver de cierta manera los sucesos (como en la metáfora de los lentes), y por tanto, orientar su comprensión. La respuesta a la pregunta “¿Qué es lo que sucede aquí?” es posible si los sujetos disponen de marcos básicos de comprensión que anteceden a los eventos de la vida cotidiana y a los cuales se acude para definir la situación, de manera que tales definiciones responden a principios de organización que se ponen en funcionamiento en el proceso del framing o encuadre. Ahora bien, los procesos de interpretación del mundo pueden y suelen exceder los marcos, de manera que no se trata de asumir una visión determinista entre el marco y la percepción-definición de la realidad; por ejemplo, de acuerdo con Butler (26), [e]l marco que pretende contener, vehicular y determinar lo que se ve [...] depende de las condiciones de reproducibilidad para su
} 
La disputa por la unidad en el discurso político colombiano: una lectura erística

la construcción de objetos de discurso en pugna, a través de los cuales se dio a ver, de manera enfrentada, cada versión de la realidad y se le presentó como verdadera en contraste con la versión supuesta e intencionalmente falsa que proponía el enemigo. Acudo aquí a la relación entre tres nociones fundamentales para el abordaje de esa disputa entre los actores: esquematización, objetos discursivos y discurso verdadero.

Desde el punto de vista de la lógica natural, el estudio de la esquematización (Grize) permite comprender los modos en que los interlocutores influyen y orientan recíprocamente su percepción de la realidad, a través de la construcción de esquemas o microcosmos, esto es, reconstrucciones cognitivas del mundo. Un esquema discursivo da a ver y hace adherir a un punto de vista particular. El dar a ver se materializa en imágenes, convierte los objetos del pensamiento (percepciones) en objetos de discurso (comunicables), que se alimentan de representaciones sociales y de preconstruidos culturales. Ese dar a ver, que constituye la esquematización, requiere una selección de haces de rasgos o propiedades de la realidad que se ponen de relieve, se relacionan y se disponen en esquemas de acción; al hacerlo, dejan en segundo plano otras propiedades, relaciones y acciones, de acuerdo con el propósito de la esquematización. Se trata de una suerte de iluminación de los aspectos que el locutor quiere hace ver y percibir sobre la realidad:

Los objetos de discurso deben ser iluminados, lo que implica poner en evidencia algunas de sus facetas y ocultar otras. Además, toda iluminación colorea de un modo particular aquello que ilumina por el hecho mismo de producirse a través de preconstruidos culturales (Grize 50).

El marco de estas operaciones de construcción y reconstrucción de la realidad, implica el uso de una visión no referencial del significado, es decir, la negación de una relación especular entre las palabras y las cosas. Los objetos de discurso no son los objetos del mundo, precisamente porque los designan (categorizan y recategorizan) de modos particulares $\mathrm{y}$, al hacerlo, los trasforman en y a través del discurso. La construcción y reconstrucción de objetos de discurso no daría cuenta, entonces, de un proceso de referencialidad sino de uno de referenciación, que implica,

éxito». 
en favor de una concepción constructivista de la referencia [...] asumir plenamente el postulado según el cual los llamados 'objetos de discurso' no preexisten naturalmente a la actividad cognitiva e interactiva de los sujetos hablantes, sino que deben ser concebidos como productos -fundamentalmente culturales- de esa actividad (Apothéloz y ReichlerBéguelin 228).

Desde ese punto de vista, el discurso construye aquello a lo que se refiere, al mismo tiempo que es tributario de esa construcción (Koch 48), esto es, las construcciones del discurso apelan a los preconstruidos culturales, pero también ayudan a reforzarlos y a alimentar esa memoria compartida. La noción de referenciación permite operar analíticamente más allá de la relación entre las palabras y las cosas, para concentrarse en las versiones del mundo que son elaboradas públicamente, evaluadas en términos de adecuación a las finalidades prácticas y a las acciones en curso de los enunciadores (Mondada y Dubois). De este modo, el estudio de las formas de referenciación en la construcción de objetos de discurso no se limita a la localización de segmentos lingüisticos que recuperan referentes en la progresión textual, sino que se pregunta por la activación de los preconstruidos culturales y el valor persuasivo de las formas de categorización y recategorización de los objetos, que pueden orientar al interlocutor hacia determinadas conclusiones en la construcción del sentido (Koch 40).

En los procesos involucrados en la referenciación, las propiedades, relaciones y acciones de los objetos de discurso esquematizados tienen que parecer verosímiles. La esquematización debe construir también modos de veridicción, de manera que el esquema, además de convincente, aparezca como verdadero para aquel que está llamado a reconstruirlo (Grize 48).

Foucault (1994 364) define el término veridicción como "las formas en que se articulan los diferentes discursos susceptibles de ser juzgados verdaderos o falsos, en un campo particular"; en estas articulaciones se "juega" la verdad, en el sentido en que se establece el conjunto de reglas y procedimientos a través de los cuales se la produce; de allí que Foucault proponga que "toda verdad se comprenda a partir de un juego de veridicción" (2010 238), y por tanto, que se le considere como una práctica situada, sin 
La disputa por la unidad en el discurso político colombiano: una lectura erística

instancia suprema. La expresión "juegos de verdad" o "veridicción" pretende enfocar el análisis de la verdad en las reglas y procedimientos que la construyen; así, sugiere

[p]or «verdad», entender un conjunto de procedimientos reglamentados por la producción, la ley, la repartición, la puesta en circulación, y el funcionamiento de los enunciados. La «verdad» está ligada circularmente a los sistemas de poder que la producen y la mantienen, y a los efectos de poder que induce y que la acompañan (Foucault 1979 189).

Ese doble efecto de poder, que induce y acompaña la producción de veridicciones, configura una "economía política de la verdad", en el sentido de las luchas entre los discursos que se la atribuyen, es decir, que la lucha por adueñarse de la verdad es al mismo tiempo la lucha por producirla, toda vez que "el discurso no es simplemente aquello que traduce las luchas o los sistemas de dominación, sino aquello por lo que, y por medio de lo cual se lucha, aquel poder del que quiere uno adueñarse" (Foucault $19926)$.

El "combate por la verdad" se entiende como una lucha no "en favor" de la verdad en su singularidad totalizante, sino "acerca de la verdad" o en torno a lo verdadero como estatuto, a través del juego que discrimina lo verdadero de lo falso, y con ello, de los efectos políticos de poder que se derivan de lo que logra presentarse como verdadero (Foucault 1979 188). Las formas aletúrgicas del decir, así, manifiestan los modos en que algo es presentado como verdadero, teniendo en cuenta la producción de la verdad y el acto por el cual ella afecta directamente la figura de quien la enuncia:

Se trataría de analizar, no en modo alguno cuáles son las formas del discurso que permiten reconocerlo como veraz, sino bajo qué forma, en su acto de decir la verdad, el individuo se autoconstituye y es constituido por los otros como sujeto que emite un discurso de verdad; bajo qué forma se presenta, a sus propios ojos y los de los otros, aquel que es veraz en el decir; [cuál es] la forma del sujeto que dice la verdad (Foucault 2010 19). 
El objeto discursivo unidad, esquematizado desde los discursos gubernamental y guerrillero, fue introducido en un combate aletúrgico por el contenido verdadero de esos objetos. Ellos entraron en el juego de lo verdadero y de lo falso en las arenas públicas, y se constituyeron como objeto para el pensamiento político (Foucault 1979) en medio del conflicto interno.

Hablo aquí de una erística para hacer hincapié en las fuerzas en pugna en torno a la posesión de la verdad (o como plantea Schopenhauer, el arte de tener razón a toda costa) y en los modos que asumen esas fuerzas en la construcción de objetos de discurso. Esta erística del decir verdadero nos permite pensar en el carácter agonal de la relación construida con el enemigo en y a través de los modos aletúrgicos del decir político.

La dialéctica erística, de acuerdo con el autor alemán, daría cuenta de «aquellas técnicas dadas por la naturaleza, de las que se sirve la mayoría de la gente para tener razón cuando durante una disputa advierten que no la llevan de su parte» (Schopenhauer 15). Pese a que no comparto aquí la simplificación de la erística al arsenal técnico de estratagemas de manipulación, me interesa resaltar el hecho de que relaciona agonalmente a los sujetos a través de la razón -la verdad- como un objeto en disputa, que es posible poseer, es decir, que se trata de un combate motivado por el deseo o la necesidad de mostrar que se posee la verdad. Asimismo, tomo distancia de la perspectiva evaluativa de la erística en el marco de la argumentación, que aparecen en Platón y en Aristóteles como una crítica negativa contra los sofistas, al presentar sus modos de razonamiento como argumentaciones erísticas, en oposición a las argumentaciones dialécticas. ${ }^{2}$ Poniendo entre paréntesis esa dimensión evaluativa, retomo aquí la idea de

\footnotetext{
2 "[E]l que dirige su mirada a las cosas comunes con arreglo al objeto en cuestión es un dialéctico; el que hace esto de manera sólo aparente es un sofista. Y un razonamiento erístico y sofístico es, en un caso, el que es sólo aparente razonamiento y versa en torno a las cuestiones sobre las que la dialéctica es crítica [...] En efecto, así como la falta <cometida> en una competición tiene una forma específica y es como un combate ilegítimo, así también en la controversia la erística es un combate ilegítimo: pues allí los que se proponen vencer por todos los medios echan mano de todo, y también aquí los erísticos $<$ hacen lo mismo $>$ [...] y tanto los amigos de pendencias como los sofistas <se sirven $>$ de los mismos argumentos, pero no con miras a las mismas cosas, y un mismo argumento será sofístico, pero no en el mismo aspecto, sino que, en cuanto sea por mor de una aparente victoria, será erístico, y en cuanto sea por mor de una aparente sabiduría, será sofístico" (Aristóteles, 256-257).
} 
La disputa por la unidad en el discurso político colombiano: una lectura erística

que el argumento erístico, en esos términos, es el argumento que se propone como objetivo la victoria a cualquier costo; por tanto, el término erística nos permite concentrarnos en iluminar la construcción de objetos de discurso desde el interés en la disputa misma por ese decir verdadero que se construye para vencer al enemigo.

\section{Nota metodológica}

Las reflexiones propuestas en este texto se derivan de la investigación titulada "Construcciones retóricas de la oposición política en el conflicto armado colombiano: los discursos de las FARC-EP y del presidente Juan Manuel Santos (2010-2012)", cuyo informe de resultados fue aceptado en 2017 como tesis doctoral en Linguística en la Universidad de Buenos Aires (Olave 2017 2019b). Desde una perspectiva interpretativa interdisciplinar (Arnoux 2009 2019), se analiza un corpus multimodal compuesto por todas las comunicaciones públicas emitidas por los actores sociales durante el bienio que antecede al inicio del proceso de paz en Colombia que se llevó a cabo en La Habana, Cuba.

En el análisis específico de este artículo se examina la composición textual e interdiscursiva de un sintagma fijo en el corpus, categorizado inductivamente y estudiado desde la noción de objeto de discurso (Koch), esquematización (Grize) y aleturgia (Foucault 2010). El método seguido se basa en el procedimiento interpretativo propuesto para el análisis erístico de disputas públicas (Olave 2019a).

\section{La unidad como urgencia para la revolución y la prosperidad}

La disputa por el objeto discursivo unidad se libra en torno al contraste entre componentes asociados, relaciones establecidas y acciones focalizadas por cada discurso, a medida que van construyendo ese objeto en sus comunicaciones. Los componentes que los discursos gubernamental y guerrillero asocian a la unidad son disímiles: mientras que 
el primero hace referencia a la gobernabilidad, la política de desarrollo económico y de seguridad antiterrorista, el decir insurgente presenta la unidad ligada a la lucha popular, la resistencia armada y el establecimiento de un contrapoder alternativo al Gobierno. En cuanto a las relaciones que se entrecruzan en el objeto discursivo, el decir gubernamental anuda los componentes que involucra en la memoria neoliberal (modelo de Nueva Gerencia Pública y de Tercera vía), el discurso antiterrorista estadounidense, la tesis de la derrota militar insurgente y la apelación a la memoria independentista nacional. El discurso guerrillero, por su parte, relaciona los componentes identificados con la memoria socialista y bolivariana, dentro de los cuales la unidad queda adherida al regionalismo y al antiimperialismo, propios de la matriz latinoamericanista. En el ámbito de las acciones focalizadas en cada discurso, se oponen las construcciones ligadas al trabajo conjunto para la obtención de resultados, contra las acciones encaminadas a la confrontación y la resistencia popular; puede decirse que se contrastan movimientos que focalizan la acción y la reacción, el trabajar juntos contra el luchar juntos, esto es, una unidad gubernamental como alineación de acciones, contra otra unidad guerrillera, como rechazo contra esas acciones. En la Tabla 1 se sintetizan los elementos mencionados.

En el discurso gubernamental, el objeto unidad fue construido como parte fundamental del proyecto de gobierno de la Prosperidad democrática. Así se manifestó en el discurso de posesión presidencial, dedicado principalmente a ratificar la intención de gobernar desde lo que se llamó la Unidad Nacional:

[H]oy reitero solemnemente, en esta histórica Plaza de Bolívar, que presidiré un Gobierno que será de Unidad Nacional y que buscará la prosperidad social para todos los colombianos [...] En el Bicentenario de nuestra Independencia es más oportuno que nunca que los colombianos nos decidamos por la unión y no por la confrontación [...] Cada país de nuestra región tiene grandes fortalezas, pero si trabajamos juntos ipodemos ser una gran potencia! Por eso creemos firmemente en la unidad y la confraternidad latinoamericana, que son el legado de nuestros Libertadores y el imperativo de nuestros tiempos [...] Llegó la hora de edificar -unidos, como debe ser- un país que nos llene de orgullo, un país digno para nuestros hijos (Santos, 2010, agosto 7). 
La disputa por la unidad en el discurso político colombiano: una lectura erística

\section{Tabla 1.}

Esquematización del objeto discursivo Unidad

\begin{tabular}{|c|c|c|c|c|}
\hline Discurso & $\begin{array}{l}\text { Componentes del objeto de } \\
\text { discurso }\end{array}$ & $\begin{array}{l}\text { Relaciones } \\
\text { interdiscursivas }\end{array}$ & $\begin{array}{l}\text { Acciones } \\
\text { focalizadas }\end{array}$ & Ejemplos \\
\hline Gubernamental & $\begin{array}{l}\text { Gobernabilidad (Buen } \\
\text { gobierno, institucionalidad, } \\
\text { optimismo, prosperidad, } \\
\text { esperanza, libertad) } \\
\text { Política de desarrollo } \\
\text { económico (integración } \\
\text { comercial, competitividad, } \\
\text { productividad agrícola, } \\
\text { inversión, empresas, } \\
\text { emprendimiento) } \\
\text { Política de seguridad } \\
\text { antiterrorista (paz, violencia, } \\
\text { Fuerza Pública, defensa, } \\
\text { reparación a víctimas) }\end{array}$ & $\begin{array}{l}\text { Modelo de Nueva } \\
\text { Gerencia Pública. } \\
\text { Modelo de } \\
\text { Tercera Vía. } \\
\text { Política antiterrorista } \\
\text { estadounidense. } \\
\text { Tesis de "el fin del } \\
\text { fin" de las Farc. }\end{array}$ & $\begin{array}{l}\text { Trabajar juntos, } \\
\text { definir la } \\
\text { unidad, creer en } \\
\text { ella, edificarla, } \\
\text { construirla, } \\
\text { convocar y } \\
\text { congregar a la } \\
\text { unidad, unirse } \\
\text { para buscar, } \\
\text { lograr, producir } \\
\text { o hacer cosas. }\end{array}$ & $\begin{array}{l}\text { Y el Buen Gobierno } \\
\text { se } \\
\text { potencia aún más } \\
\text { muchísimo más, si se } \\
\text { complementa y si se } \\
\text { implementa en un } \\
\text { entorno de UNIDAD } \\
\text { NACIONAL, para } \\
\text { que } \\
\text { esa unidad nacional } \\
\text { busque en los } \\
\text { grandes propósitos } \\
\text { nacionales los } \\
\text { grandes propósitos } \\
\text { sociales } \\
\quad \text { (Santos } 2011 \text { abril 28) }\end{array}$ \\
\hline Guerrillero & $\begin{array}{l}\text { Lucha popular (fuerza, } \\
\text { movilización, pueblo, } \\
\text { comunidades, sentir popular, } \\
\text { organización, batalla, } \\
\text { democracia, independencia, } \\
\text { paz) } \\
\text { Resistencia armada } \\
\text { (levantamiento, rebelión, } \\
\text { insurrección, revolución, } \\
\text { vanguardia) }\end{array}$ & $\begin{array}{l}\text { Memoria socialista. } \\
\text { Memoria } \\
\text { bolivariana. } \\
\text { Latinoamericanismo. }\end{array}$ & $\begin{array}{l}\text { Luchar juntos, } \\
\text { unir fuerzas, ser } \\
\text { más poderosos, } \\
\text { actuar, resistir, } \\
\text { levantarse } \\
\text { unidos contra..., } \\
\text { movilizarse, } \\
\text { organizarse, } \\
\text { insurreccionarse, } \\
\text { derrotar el } \\
\text { sectarismo y las } \\
\text { oligarquías, } \\
\text { triunfar. }\end{array}$ & $\begin{array}{l}\text { En estos } 47 \text { años de } \\
\text { batallas por la paz de } \\
\text { Colombia desde la } \\
\text { resistencia armada, } \\
\text { nos ratificamos en el } \\
\text { empeño de la } \\
\text { reconstrucción y } \\
\text { reconciliación de la } \\
\text { Colombia bolivariana, } \\
\text { la patria grande y el } \\
\text { socialismo, } \\
\text { iluminados por el } \\
\text { pensamiento unitario } \\
\text { del libertador Simón } \\
\text { Bolívar. Porque la } \\
\text { unidad y la paz sí son } \\
\text { posibles. } \\
\text { (FARc-EP, 2011, mayo 28) }\end{array}$ \\
\hline
\end{tabular}


La activación de la memoria independentista dotó al objeto unidad del sentido de confraternidad regional y permitió presentarla como legado de las grandes gestas decimonónicas. Es importante resaltar que se trata de una actualización de la memoria independentista centrada más en la construcción del Estado que en las gestas revolucionarias, como sucede en el discurso guerrillero. La referencia al lugar de la locución y a la coyuntura del Bicentenario ancló la unidad a la conmemoración histórica y a la responsabilidad por la continuidad de esa herencia libertaria. A partir de esa relación establecida, la libertad entra a formar parte de las metas de gobierno: liberarse de las divisiones, de los odios y de la polarización, en función de la construcción institucional de la República. La traducción de esa responsabilidad fue la presentación de la unidad como urgencia social; la nominalización el imperativo de nuestros tiempos explicita ese sentido de urgencia que aparece en los discursos santistas y que ejemplifico aquí con los resaltados. En otras comunicaciones, ese imperativo se traduce en formas condicionales que presentan la unidad como requisito de la prosperidad:

Muchas veces me preguntan de qué se trata la Unidad Nacional, y cómo se traduce en la realidad. Y aquí está la respuesta: iDe esto se trata la Unidad Nacional! Hoy más que nunca, en este recinto, está plasmado ese espíritu de Unidad Nacional que he convocado a través de los últimos meses. No es, como siempre se ha dicho, una unidad para repartir puestos ni para repartir prebendas. No es una unidad para acallar las voces de los opositores, que son tan importantes para la democracia. Es una unidad en torno a los temas fundamentales que a todos nos congregan y que a todos nos tienen que seguir congregando. Una unidad para generar empleo y para combatir la pobreza. Una unidad para crear prosperidad democrática, es decir, prosperidad social para todos los colombianos. Nuestro país tiene todos los elementos, todas las condiciones, para despegar y convertirse en un milagro económico y social. Pero eso sólo lo vamos a poder lograr si trabajamos unidos, si nos ponemos todos unas metas comunes, si empujamos todos en la misma dirección (Santos 2010 agosto 19).

Bajo la necesidad de definir la Unidad Nacional y de protegerla contra las críticas, el discurso gubernamental debió acudir a la negación directa de las prácticas de repartición de puestos ('cuotas políticas') y de intención de gobernar desde la unanimidad de las coaliciones. Las nominalizaciones dispuestas en paralelismo y en reformulaciones intradiscursivas (ver cursivas en la cita) pretendieron reforzar esa conversión de la visión 
La disputa por la unidad en el discurso político colombiano: una lectura erística

negativa sobre la unidad en visión positiva, como requisito o imperativo para el milagro económico y social prometido en las comunicaciones. El efecto de los paralelismos está ligado a la reiteración eufónica y la focalización en las propiedades positivas del objeto en construcción: los componentes que se resaltan controvierten la posibilidad de que un gobierno de unidad no sea más que una cooptación de la divergencia y el pago de compromisos políticos adquiridos con sectores influyentes en la dinámica económica y burocrática del país. El proyecto de Unidad Nacional fue presentado precisamente en una vía contraria: la conformación del gabinete de gobierno sería más técnica y se invitó a participar en él a los sectores de oposición.

Estas alianzas se anunciaron desde la campaña presidencial y tuvieron poder de convocatoria, tanto en los partidos que se acogieron a la coalición como entre la población civil, que se percató de un cambio en el tono conciliador, institucional y gerencial del Gobierno santista, frente al tono exacerbado y confrontativo que había instalado el expresidente Uribe (Vargas 128-130). La construcción del objeto Unidad Nacional, desde los primeros discursos de gobierno, le permitió a Santos determinar los propósitos comunes en clave de urgencia. De ahí que desde la unidad como imperativo se mostrara a sí mismo como el político movido por intereses superiores a la política misma; se trata de la figura del demócrata liberal que gobierna más allá de sus intereses personales y es capaz de pactar con los enemigos en razón del bien común, neutralizando la confrontación entre intereses políticos divergentes (Vásquez Ramírez). Ese tono concertador y moderado forma parte de las relaciones establecidas con el discurso de la Nueva Gerencia Pública y la Tercera vía: el presidente, como un gerente experto, dejaría de lado las disputas para concentrarse en la eficacia y la eficiencia del proyecto administrativo.

Así, el componente de la gobernabilidad, que hace al objeto de discurso unidad, se expresó en propiedades que remiten al proyecto del Buen Gobierno y a valores como la institucionalidad, el optimismo y la prosperidad nacional. La gobernabilidad fue presentada como un efecto de la Unidad Nacional, a través de reformulaciones intradiscursivas y nominalizaciones encadenadas: 
Prosperidad PARA Todos, Prosperidad CON Todos. iDe eso se trata la Unidad Nacional a la que hemos convocado! (Santos, 2011, abril 29, mayúsculas originales).

En el caso nuestro, la gobernabilidad, la Unidad Nacional, nos ha dado una gobernabilidad envidiable. Todo el mundo nos dice: qué maravilla, ese país tiene una gobernabilidad que le ha permitido mantener esa economía como está (Santos 2012 julio 27).

La reformulación de la «prosperidad para todos» a la «prosperidad con todos», y la recategorización de ambas nominalizaciones como Unidad Nacional, deja claro que se trataba de iluminar positivamente el proyecto de coalición de los partidos políticos y las bancadas de gobierno. El discurso de la prosperidad permitiría contrarrestar los ecos negativos y los vicios de esas alianzas, haciendo de la unión un imperativo y una urgencia colectiva. En la cita de 2012, las nominalizaciones que van reformulando el objeto unidad como gobernabilidad se orientan hacia la celebración de los indicadores económicos; los componentes de la política de desarrollo van apareciendo así, asociando la unidad con factores como la integración comercial, la competitividad, la productividad agraria y el emprendimiento, entre otros:

[U] nidos nos volvemos más atractivos, somos un mercado más importante porque nos volvemos más competitivos. Eso trae más inversión, que produce más bienes, más servicios. Y eso genera empleo y el empleo se traduce en más prosperidad. Así desencillo, pero así de contundente (Santos 2011 abril 28).

[L]a integración de los pueblos, la integración de los países, es tal vez de las teorías económicas que nunca se han controvertido. Cuando se unen los pueblos, cuando se unen los países para buscar objetivos comunes, siempre los alcanzan con más facilidad. Divididos es más difícil. Unidos es más fácil. Por eso la tendencia a nivel mundial es hacia la integración. Desde la década de nuestros libertadores. Simón Bolívar decía: sueño con una América Latina integrada. Porque desde entonces esa tesis de la integración era válida (Santos 2011 abril 28).

A través de los paralelismos el discurso encadena, en clave causal, los aspectos positivos de la unidad dentro de la política macroeconómica. La palabra encuentra en el tono asertivo y en las reiteraciones paralelas cierto efecto didáctico que construye el 
La disputa por la unidad en el discurso político colombiano: una lectura erística

objeto como objeto verdadero, desde el tono de la experticia: la unidad es sencilla, pero contundente; es una teoría económica que nunca se ha controvertido; es una tendencia a nivel mundial y es válida históricamente. La asertividad suele devenir en condicionalidad, a partir de la urgencia de las acciones:

Este país está a punto realmente de despegar si hacemos las cosas bien y si mantenemos ese espíritu de unidad, ese espíritu de hacer las cosas entre todos, porque la historia nos ha enseñado: los países que se unen como sociedad para buscar grandes metas y grandes objetivos, ahí es cuando se hacen las grandes transformaciones, cuando hay optimismo (Santos 2011 agosto 22).

Eso es posible si todos unidos, todos juntos trabajamos buscando los mismos objetivos, si dejamos de matarnos los unos a los otros, si dejamos de insultarnos los unos a los otros, si nos respetamos las diferencias. En este país hay riqueza para todos y la podemos producir cada vez más si trabajamos juntos (Santos 2012 febrero 11).

En el orden de la política de seguridad antiterrorista, el objeto unidad pone de relieve las operaciones militares contra la guerrilla presentándolas como resultados en el tramo final del conflicto armado, esto es, desde la tesis del fin del fin. En este ámbito, la unidad se traduce en los cambios introducidos en la política de seguridad y defensa nacional (Ministerio de Defensa), al respecto de la coordinación entre unidades militares (policía y ejército nacional) ${ }^{3}$ para la ejecución de operativos de contraguerrilla:

ese trabajo conjunto siempre produce algo que también necesitamos y que el pueblo colombiano también espera: resultados, resultados, cada vez más resultados para que ese tramo final dure el menor tiempo posible y lleguemos finalmente a ese país en paz que todos añoramos. Fue un trabajo conjunto de nuestras Fuerzas, que demuestra una vez más

\footnotetext{
3 "La transformación de las amenazas hace necesario intensificar el proceso de trabajo conjunto y coordinado de las Fuerzas Militares y la Policía Nacional para enfrentar los desafíos de mayor complejidad o fortaleza. Una revisión profunda de los roles y misiones de las Fuerzas y la Policía, para profundizar especialización y eliminar conflictivas duplicidades, se implementará al tiempo con la identificación de patrones que deben desmontarse y de cambios estructurales para incentivar esfuerzos conjuntos y coordinados que deben adoptarse" (Ministerio de Defensa 40-41).
} 
que unidos somos más fuertes, que unidos logramos lo que nos proponemos (Santos 2010 septiembre 23).

Las nominalizaciones reiteradas y paralelas orientan la visión de la seguridad nacional como una propiedad también del objeto discursivo unidad. El enunciador se inscribe a sí mismo, al pueblo y a las Fuerzas Armadas en un solo colectivo que trabaja en conjunto y obtiene resultados, que es como se categoriza a las operaciones antiguerrilleras, en este caso referidas al asesinato de alias el Mono Jojoy. El discurso de la unidad, así, permite contraponer a los violentos contra las instituciones:

Esto es decirles a los violentos 'no más violencia, no más secuestros'. Y decirle al mundo entero que Colombia está unida; Colombia está unida en torno a sus instituciones, está unida en torno a su democracia, a su libertad; y que no vamos a permitir que siga la violencia y siga el secuestro y todas esas manifestaciones del crimen, porque estamos hastiados (Santos 2011 diciembre 6).

Hoy, cuando los terroristas pretenden imponer su agenda con bombas y miedo, quiero convocar a la unidad en torno a nuestras instituciones y nuestra Fuerza Pública, para oponer al terror la fuerza de un pueblo unido, democrático y valiente (Santos 2012 mayo 23).

A través del encadenamiento de las nominalizaciones reformuladas, en la primera cita, y de la inscripción explícita de colectivos opuestos, en la segunda, se expanden los sentidos atribuidos al objeto unidad en clave de política pública de seguridad. Las comunicaciones gubernamentales durante este periodo activan constantemente la voz del antiterrorismo para contradecirlo con la unidad del pueblo, puesta como continuidad natural de la unidad militar de las tropas. En la convocatoria contra el terrorismo, como amenaza permanente que obliga a no bajar la guardia, se introduce el tono de la urgencia por la unión y la necesidad de atender a otras problemáticas sociales que quedan ligadas a la seguridad, en relación de dependencia: 
La disputa por la unidad en el discurso político colombiano: una lectura erística

La unión en torno a objetivos comunes es vital para el país porque, ahora que estamos consolidando la Seguridad Democrática -y en eso, tengan la seguridad de que no vamos a bajar la guardia un solo milímetro- podemos dirigir más y mejor nuestros esfuerzos hacia la generación de trabajo, trabajo y más trabajo para los colombianos (Santos 2010 septiembre 8).

Precisamente, bajo el lema de la consolidación de la política de seguridad democrática se pretendió suspender el antiterrorismo como la principal preocupación de la agenda gubernamental, aduciendo que se estaba cerca de la victoria militar contra la guerrilla. Temas como el desempleo (en la cita) y la paz empezarían a llenar el espacio de los discursos gubernamentales durante el primer bienio presidencial, en el intento por desplazar la seguridad en la agenda pública. La transición Uribe-Santos se caracterizó por esa tensión entre continuidad y cambio frente al manejo del conflicto armado interno: el paso de la Seguridad democrática a la prosperidad democrática fue presentado como la superación del peor momento de la guerra y la instalación de una visión posconflictiva, que ya anunciaba, sin poder decirlo, el inicio de la negociación de la paz con la guerrilla.

Las FARC-EP, como se mencionó antes, construyeron el objeto unidad asociándolo con los componentes propios de la lucha popular, la resistencia armada y el contrapoder gubernamental. En la lucha popular y la resistencia armada presentaron la unidad como movilización y levantamiento de las minorías oprimidas:

La insensibilidad y la desunión son cómplices del peor de los perjuicios. Cada habitante es una fuerza vital para defender las pertenencias de las comunidades en íntima unión y resistencia (FARC-EP 2011 febrero 16).

El momento requiere unidad y lucha, verdaderos festivales de movilización para imponer desde la calle, con la exaltación masiva del sentir popular, una ley que garantice la gratuidad educativa hasta el nivel superior (FARC-EP 2012 junio 8).

Las reiteraciones, reformulaciones intradiscursivas y nominalizaciones coordinadas (unidad y lucha; insensibilidad y desunión; unión y resistencia) caracterizan la 
presentación del objeto discursivo unidad en el decir guerrillero. A través de estos recursos se orientó la representación de las propiedades del objeto como reacción del pueblo colombiano, especialmente de sus sectores más vulnerables. Así, la unidad fue convocada a propósito de reivindicaciones sociales, como la gratuidad educativa (en la cita anterior) y la inclusión de las minorías:

El presente es de lucha y unidad para resistir la embestida de los neoesclavistas y sus lacayos pero ante todo de unidad que permita redefinir con autonomía, políticas públicas de inserción social para las comunidades negras (FARC-EP 2011 marzo).

A través del gesto anti-imperialista -al que remite, por ejemplo, la acusación de neoesclavistas y sus lacayos- se convocó al pueblo a la insurrección y a la conformación de un contrapoder gubernamental que removiera el dominio de las oligarquías y del gran imperio. Igual que el discurso santista, el guerrillero construye el objeto unión bajo el cariz de la urgencia y la necesidad, en este caso, de reacciones armadas contra la política hegemónica:

[E]s necesario que los pueblos se levanten al unísono con la antorcha de la libertad en una mano y el fusil de Marulanda en la otra, haciendo uso legítimo de su derecho universal a la rebelión, para romper cadenas y construir mundos nuevos como lo soñó este histórico líder, sobre las ruinas insepultas de un gran imperio (FARC-EP 2011 abril 8).

[S]olo el camino de la UNIDAD DEL PUEBLO, derrotando el sectarismo, el espíritu de capilla, el vanguardismo, la intolerancia y otras manifestaciones de infantilismo dentro del movimiento popular, podremos construir entre todos, las herramientas necesarias para que al final, en la confluencia de todas las expresiones de lucha de nuestro pueblo, podamos alcanzar la paz democrática y derrotar el poder de las oligarquías (FARC-EP 2011 abril 29 , mayúsculas originales).

La coordinación de la antorcha de la libertad en una mano y el fusil de Marulanda en la otra llevan a construir el objeto unidad como uso legítimo del derecho universal a la rebelión, esto es, que se anudan la unión y la rebelión a través de los resaltes 
La disputa por la unidad en el discurso político colombiano: una lectura erística

esquematizados en las nominalizaciones. Asimismo, la Unidad del pueblo se reformula en la segunda cita- como la confluencia de todas las expresiones de lucha de nuestro pueblo, con lo cual los elementos propios de la revolución terminan definiendo el objeto discursivo unidad en el discurso guerrillero. Al final de la primera cita, además, el antimperialismo se articula con el latinoamericanismo que emerge de la activación de la memoria bolivariana. El tópico de la Patria Grande, reformulación de Nuestra América, vuelve a la figura de Bolívar para sostener el llamado urgente a la unión regional, pero en esta discursividad, desde la lucha armada y la violencia revolucionaria contra el capitalismo:

Nuestra labor es salvar a Nuestra América de las garras del imperialismo y trabajar juntos por la construcción de la Patria Grande (FARC-EP 2011 diciembre).

¿Qué hace falta? Unidad política e ideológica al interior de la vanguardia revolucionaria en torno a la táctica frente a una revolución inminente (FARC-EP 2012 abril).

Camaradas: la actual crisis estructural del capitalismo reclama con urgencia la unidad de los pueblos, para la lucha que ya se configura en el horizonte (FARC-EP 2011 agosto 7).

Las nominalizaciones de la revolución inminente y la urgencia de la unidad de los pueblos forman parte del diagnóstico del capitalismo en crisis, desde la visión guerrillera. El sentido de la fragmentación del mundo y el privilegio de las individualidades, particularmente de las élites en el poder, se va a contrastar con la idealización de la unidad como reconciliación social y reconstrucción de lo nacional. Es a través de estas orientaciones del sentido como el discurso fariano coordina unidad con movilización, lucha y violencia armada. En los llamados a la unidad de todos, estos últimos son especificados en la reformulación como todas las organizaciones y expresiones de lucha; de ahí que los movimientos sociales y la protesta civil entren a formar parte del objeto unidad construido por el discurso guerrillero:

[S]erá la movilización y la unidad de todos, de todas las organizaciones y expresiones de lucha como será posible alcanzar la reconciliación y la reconstrucción de la nación (FARCEP 2011 mayo 28) 
La protesta social, entonces, será presentada como la verdadera Unidad Nacional, en contraposición con lo que aparece en el discurso guerrillero como una supuesta Unidad Nacional de élites. Esa falsa Unidad Nacional estaría basada en el engaño a la ciudadanía, apoyados por los medios de comunicación y el aparato militar:

[A]hora confluyen en una supuesta Unidad Nacional de élites, más preocupados en el reparto del presupuesto estatal, los cargos y las cuotas de poder; que por arremeter con seriedad y profundidad en la solución de los graves problemas que afectan al ciudadano del común (FARC-EP 2011 agosto 8).

$\mathrm{Su}$ nuevo ropaje demagógico llamando a conformar una falsa "Unidad Nacional" caracterizada por el apoyo incondicional a un orden social desigual e injusto, apuntalado en el militarismo y en la cohesión ideológica de los grandes medios de comunicación para garantizar la impunidad, no es más que otro engaño para ocultar la imposición de nuevas medidas antipopulares que ya vienen en marcha (FARC-EP 2011 abril 30).

En la disputa por la 'verdadera' unidad, el llamado a la unión (nacional e internacional) contrasta las componentes, relaciones y acciones focalizadas en la esquematización del objeto unidad en cada discurso. El decir gubernamental es acusado de demagogia y de engaño, mientras que la palabra guerrillera -según el discurso santista- no es más que acción terrorista: un hacer violento que desplaza el decir o lo reemplaza completamente en el escenario bélico. El mayor esfuerzo en la lucha por la veridicción de la unidad aquí está, evidentemente, del lado del discurso de reacción; es el decir guerrillero el que debe desmentir la unidad del gobierno, en tanto que nombre del proyecto gubernamental y que acciones políticas programadas o adelantadas.

No obstante, no quiere decir esto que el discurso santista no tuviera parte en la disputa por el decir verdadero sobre la unidad; por el contrario, los reiterados llamados a la unión en torno a la Fuerza Pública, sobre todo en momentos coyunturales del conflicto bélico (como los ataques armados de la guerrilla), demostraron que su implicación en la lucha no fue menor: por un lado, había que contradecir la dilución que el discurso guerrillero venía realizando de la tropa insurgente en los movimientos sociales, por lo cual debía convocarse al rechazo popular de la guerrilla, reformulada como unión contra el terrorismo; por otro lado, había que reforzar la tesis del fin del fin 
La disputa por la unidad en el discurso político colombiano: una lectura erística

o, a lo sumo, contradecir la idea de que la protesta social estaba alineada con los intereses y reivindicaciones de la guerrilla. La vía para abordar estos propósitos fue la construcción del objeto unidad como política de gobernabilidad, de desarrollo económico y de seguridad nacional.

\section{Pausa}

El tópico de la unidad ha sido recurrente en el discurso político en general e, inclusive, ha estructurado la propaganda de proyectos de poder. Desde el punto de vista de la matriz de los discursos latinoamericanistas, Arnoux (2008) demuestra que el pensamiento sobre la unión americana está atravesado por un rasgo común de idealización dentro de sus diversos componentes. La unidad es épica y es utópica; de ahí que el latinoamericanismo sea activado en términos de gesta libertaria y de responsabilidad histórica. En esa idealización del pasado independentista reside su activación relativamente automática en el presente y su proyección hacia el futuro; ideales atemporales que hacen de la unidad un objeto discursivo poderosamente convocante en la región. Pero precisamente esa memoria compartida hace de la unidad un objeto susceptible de activación desde cualquier orilla ideológica y para cualquier proyecto político, igual que sucede con la figura de Bolívar, que le es adyacente. La apropiación del sentido de ese objeto no es menor: quien logre definirlo en los términos y componentes que más convengan, podrá capitalizar su aceptabilidad en el espacio público, sin mayores esfuerzos persuasivos.

Paradójicamente, en el conflicto armado interno la disputa por la unidad verdadera contribuyó a la afirmación de su contrario: la fragmentación y sectarización en el país. El periodo 2010-2012 no fue un momento de unión de fuerzas sociales en torno a propósitos nacionales, ni de reconciliación entre fuerzas políticas antagónicas, pese a la coalición de gobierno lograda. Por el contrario, durante ese bienio las posturas en torno al conflicto armado se radicalizaron y formaron bloques sectarios a favor y en contra del 
manejo de la seguridad en el país: se trataba de la reacomodación de la guerrilla y la reestructuración de fuerzas y estrategias en el conflicto durante su etapa más inercial.

Si la búsqueda de una Unidad Nacional se proponía, sin hacerlo explícito, la preparación del terreno social para el giro político de la paz negociada, se trató de un proyecto gubernamental que obtuvo exactamente su contrario. En esas condiciones de fragmentación social se desarrollaron los diálogos de paz en La Habana, Cuba; una parte sustancial de sus resultados actuales parece relacionarse directamente con esa pugna por la unidad, discurso que los sectores políticos siguen disputando en el escenario del postacuerdo en Colombia.

\section{Referencias}

Apothéloz, Denis y Marie-José, Reichler-Béguelin. "Construction de la référence et stratégies de désignation". Du syntagme nominal aux objets-de-discours. Editado por Alain Berrendoner y Marie-José Reichler-Béguelin. Neuchâtel: Universidad de Neuchâtel, 1995, 227-271. Impreso.

Aristóteles. "Tópicos". Tratados de Lógica. Madrid: Gredos, 2007, 67-233. Impreso. Arnoux, Elvira Narvaja. El discurso latinoamericanista de Hugo Chávez. Buenos Aires: Biblos, 2008. Impreso.

Arnoux, Elvira Narvaja. Análisis del discurso. Modos de abordar materiales de archivo $2^{\underline{a}}$ ed., Buenos Aires: Santiago Arcos, 2009. Impreso.

Arnoux, Elvira Narvaja. "El Análisis del discurso como campo académico y práctica interpretativa". Métodos de Análisis del Discurso. Perspectivas argentinas. Editado por Óscar Iván Londoño y Giohanny Olave. Bogotá: Ediciones de la U, 2019, pp. 17-18. Impreso.

Butler, Judith. Marcos de guerra. Las vidas lloradas. Barcelona: Paidós, 2010. Impreso. FARC-EP. Febrero 16 de 2011. Catatumbo... En peligro inminente y alerta máxima. Archivo de investigación. Sin datos editoriales.

FARC-EP. “Llegó el león al Chocó”. Revista Resistencia, Vol. Marzo, 2011, 25-27. 
La disputa por la unidad en el discurso político colombiano: una lectura erística

FARC-EP. Documento Secretariado al 3er. Aniversario. Abril 8 de 2011.

FARC-EP. Celebremos el primer aniversario del surgimiento del Movimiento Bolivariano. Abril 29 de 2011.

FARC-EP. iA la calle, a protestar el 1 de mayo! Abril 30 de 2011.

FARC-EP. 47 años de batallas por la paz de Colombia desde la resistencia armada. Mayo 28 de 2011.

FARC-EP. Saludo. Comisión Internacional de las FARC-EP. Agosto 7 de 2011.

FARC-EP. La estirpe soberbia del Estado. Agosto 8 de 2011.

FARC-EP. "12 de octubre: memoria y resistencia". Revista Resistencia,Vol. Diciembre, 2011, 48-50.

FARC-EP. "Lenin, el periódico y la unidad de izquierda". Revista Resistencia, Vol. Abril, 2012, 24-27.

FARC-EP. Declaración pública iQue vivan los estudiantes! Junio 8 de 2012.

Foucault, Michel. "Verdad y poder". Microfísica del poder. Madrid: La Piqueta Ediciones, 1979, 175-189. Impreso.

Foucault, Michel. El orden del discurso. Buenos Aires: Tusquets, 1992. Impreso.

Foucault, Michel. "Veridicción". Estética, ética y hermenéutica. Obras esenciales, III. Barcelona: Paidós, 1994, 363-368. Impreso.

Foucault, Michel. El coraje de la verdad: el gobierno de sí y de los otros II. Curso en el Collège de France (1983-1984). Buenos Aires: Fondo de Cultura Económica, 2010. Impreso.

Goffman, Erving. Frame analysis. Los marcos de la experiencia. Madrid: Siglo XXI, 2006. Impreso.

Grize, Jean-Blaize. "El punto de vista de la lógica natural: demostrar, probar y argumentar". La argumentación, hoy. Editado por Mariane Doury y Sophie Moirand. Madrid: Montesinos, 2004, 43-53. Impreso.

Koch, Ingedore. As tramas do texto. Río de Janeiro: Nova Fronteira, 2014. Impreso.

MinDefensa (Ministerio de Defensa de Colombia). Política integral de seguridad y defensa para la prosperidad. Bogotá: Imprenta Nacional, 2011. Impreso. 
Mondada, Lorenza y Danièle Dubois. "Construction des objets de discours et catégorisation: une approche des processus de référenciation". Du syntagme nominal aux objets-de-discours. Editado por Alain Berrendonner et Marie-José ReichlerBeguelin. Neuchâtel: Universidad de Neuchâtel, 1995, 273-302. Impreso.

Olave, Giohanny. "Construcciones retóricas de la oposición política en el conflicto armado colombiano. Los discursos de la guerrilla Farc-Ep y del presidente Juan Manuel Santos (2010-2012)". Tesis de doctorado en lingüística, Universidad de Buenos Aires, Argentina. 2017. http://repositorio.filo.uba.ar/handle/filodigital/6145

Olave, Giohanny. Análisis del discurso en disputas públicas. Retorno a la Erística. Bucaramanga: Ediciones UIS, 2019a. Impreso.

Olave, Giohanny. Retórica de la victoria. Oposición política y paz con las Farc-Ep. Bucaramanga: Ediciones UIS, 2019b. Impreso.

Santos, Juan Manuel.iLe llegó la hora a Colombia! Discurso de posesión presidencial. Presidencia de la República. Agosto 7 de 2010.

Santos, Juan Manuel. Palabras del Presidente de la República, Doctor Juan Manuel Santos, en la presentación del Proyecto de Ley de Formalización y Primer Empleo. Presidencia de la República. Agosto 19 de 2010.

Santos, Juan Manuel. Palabras del Presidente Juan Manuel Santos Calderón en el Congreso Nacional de Comerciantes. Presidencia de la República. Septiembre 8 de 2010.

Santos, Juan Manuel. Alocución del Presidente Juan Manuel Santos Calderón, luego de la baja de alias el 'Mono Jojoy'. Presidencia de la República. Septiembre 23 de 2010.

Santos, Juan Manuel. Palabras del Presidente Juan Manuel Santos en la apertura del foro 'Expogestión Caribe 2011'. Presidencia de la República. Abril 28 de 2011.

Santos, Juan Manuel. Palabras del Presidente Juan Manuel Santos en la instalación del Congreso de Acopi. Presidencia de la República. Agosto 22 de 2011.

Santos, Juan Manuel. Palabras del Presidente Juan Manuel Santos en la marcha por la libertad de los secuestrados. Presidencia de la República. Diciembre 6 de 2011.

Santos, Juan Manuel. Palabras del Presidente Juan Manuel Santos en la Marcha Encuentro de Apoyo a la Ley de Víctimas y de Restitución de Tierras. Presidencia de la República. Febrero 11 de 2012. 
La disputa por la unidad en el discurso político colombiano: una lectura erística

Santos, Juan Manuel. Palabras del Presidente Juan Manuel Santos, en el acto de nombramiento de Jefes de Control Interno. Presidencia de la República. Mayo 23 de 2012.

Santos, Juan Manuel. Palabras del Presidente Juan Manuel Santos en el X Congreso Nacional de Concejales. Presidencia de la República. Julio 27 de 2012.

Schopenhauer, Arthur. Dialéctica erística o el arte de tener razón, expuesta en 38 estratagemas. Madrid: Trotta, 1997. Impreso.

Thomas, William. "La definición de la situación". Trad. E. Aladro. Cuadernos de Información y Comunicación, vol. 10, 27-31, 2005. Impreso.

Vargas, Alejo. "El gobierno de Juan Manuel Santos y su política de seguridad y defensa".Ciudad Paz-ando, vol. 4, no. 2, 9-23, 2011. https://doi.org/10.14483/2422278X.7320

Vásquez-Ramírez, Teresita. Ethos, discurso y contradiscurso. La disputa por la opinión pública durante la campaña presidencial de 2014 en Colombia a propósito de las negociaciones de paz. Pereira: Editorial UTP, 2018. Impreso. 